\title{
ABO blood group discrepancies: Study of prevalence and related factors
}

\author{
Bipin Nepal' ${ }^{1}$, MD; Bikash Shrestha², MD; Sabindra Maharjan' ${ }^{1}$ BMLT; \\ Sunil Bhasima ${ }^{1}$, CMLT; Shrawan Kumar Shrestha ${ }^{3}$, CMLT \\ ${ }^{1}$ Department of Transfusion Medicine, Grande International Hospital, Kathmandu, Nepal \\ ${ }^{2}$ Department of Wellness \& Family Medicine, Grande International Hospital, Kathmandu, Nepal \\ ${ }^{3}$ Central Blood Transfusion Service, Red Cross Society, Kathmandu, Nepal
}

\section{Corresponding author}

Bipin Nepal, MD

Email-nepalbipin@hotmail.com

Received 13 Aug 2019

Accepted 29 Oct 2019

\section{ABSTRACT}

Background:

$A B O$ discrepancy is any deviation from the expected pattern of red cell antigen grouping with serum-grouping or when the forward-grouping results do not correlate with reverse-grouping results. This study was done to determine the incidence and causes of $A B O$ discrepancies and to identify the correct blood group for safe blood transfusions.

\section{Methods:}

This is a retrospective descriptive study. It was done on 9970 samples collected between June 2017and May 2018. All ABO typing records kept at the Grande International Hospital (GIH) blood bank laboratory were reviewed.

\section{Results:}

During the study period, 9970 blood grouping tests were performed. ABO discrepancies occurred in 26 of them. Discrepancies were more prevalent in the age of 20-30 and 30-40 years. Majority were seen in patients with history of pregnancy/miscarriage (30\%) and with any Carcinoma (23\%). The most common blood group involved was B with 34\% frequency. 96\% were reverse discrepancy type, $84 \%$ with extra antibody which was resolved by incubating the sample at $37^{\circ} \mathrm{C}$ for 30 minutes signifying most probably A and B subgroups and auto/allo antibodies.

\section{Conclusion:}

This study emphasizes the need of considering $A B O$ discrepancies in blood banks for donors and recipients for safe blood transfusion to avoid any fatal complications. This discrepancy ratio of 1/384 is more than in other studied population of other countries and also higher than ABO mismatched transfusion in standard centers in Nepal. Repeat testing and investigating for ABO subgroups and auto/allo antibodies is important.

Key words: Discrepancy, ABO/Rh typing, blood transfusion 


\section{Introduction}

$A B O$ grouping is a simple, accurate, and precise procedure and for its validity, the results of cell grouping and serum grouping should agree. In $A B O$ blood group system, the sorting of human blood is based on the inherited properties of red blood cells as determined by the occurrence or absence of the antigens $A$ and $B$, which are carried on the surface of the red cells. Persons may therefore have type $A$, type $B$, type $O$, or type $A B$ blood. Blood containing red cells with type $A$ antigen on their surface has in its serum antibodies against type $B$ red cells ${ }^{1}$.

The $A, B$, and $O$ blood groups were first identified by Austrian immunologist Karl Landsteiner in $1901^{2}$.

When the red cell antigen grouping (Forward) results do not correlate with serum grouping (Reverse), a discrepancy is said to exist. In such cases, interpretation of the $A B O$ type must be delayed until the discrepancy is resolved ${ }^{3}$. In a clinical urgency, group $\mathrm{O}, \mathrm{Rh}$ - compatible RBCs can be transfused until the resolution of discrepancy ${ }^{4}$.

There are four types of $\mathrm{ABO}$ discrepancies.

- Group I discrepancies comprise the unexpected reactions in the reverse grouping due to weakly reacting or missing antibodies.

- Group II discrepancies are those from unexpected reactions in forward grouping due to weakly reacting or missing antigen.

- Group III discrepancies occur due to protein or plasma abnormalities, rouleaux formation and pseudo agglutination.

- Group IV discrepancies are of a miscellaneous group and may be due to transfusion of out of group plasma containing component, presence of cold alloantibody, or autoantibody, $\mathrm{pH}$ dependent autoantibody, a reagent dependent antibody (e.g. EDTA, paraben) and IVIG therapy (from $A B O$ isoagglutinins). Mix field agglutination with circulating red cell of more than one $A B O$ type and polyagglutination (e.g. T activation) resulting from inherited or acquire. The abnormalities of red cell membrane also constitute group IV discrepancies.

$\mathrm{ABO}$ and $\mathrm{Rh}$ blood group discrepancies account for a considerable number of reported transfusion associated reactions ${ }^{5}$. Human errors are a major contribution to blood grouping discrepancies but some errors are not unavoidable ${ }^{6,7}$, but luckily, most of these errors do not lead to a critically adverse effects. Since blood transfusion is an extended and complex process linking many steps and individuals, there is possibility for a high rate of error. $\mathrm{ABO}$ and Rh discrepancy can thus occur ${ }^{6,7,8,9}$. Most of the ABO discrepancies are due to the technical error, errors in collection, errors in documentation and registration, phlebotomy errors and occasionally due to physiological problems of the patients.

\section{Objectives}

The aim of this study was to assess the $A B O$ discrepancies which occurred during the 1 year study period and how they were handled. To the best of our knowledge, Blood types errors found on different techniques have not been published, or the subject addressed from Nepal.

\section{Materials \& Methods}

All blood bank $A B O$ typing records kept at the GIH blood bank laboratory between June 2017 to May 2018 were reviewed. The following steps were followed:

- $\quad A B O$ and Rh typing was done which included forward cell grouping and reverse serum grouping by 2 methods i.e. tube method and gel card method done through standard operating procedure. (Grande-BB-SOP01,page 3,4,6 \& 8 )

- For forward grouping reagents used were as follows:

- Anti-A and Anti B - IgM monoclonal antibody ( $A B O$ grouping)

- Anti D - IgM monoclonal antibody (Rh typing)

For reverse grouping, reagents used were as follows:

- Pooled known A, B, O cells

- Other reagents: $6 \%$ Albumin, Auto control (own cells and own serum)

For $A$ subgroup anti-A lectin was used which reacts directly with $A 1$ and $A 1 B$ but not $A 2$ or A2B red cells.

Ortho Bio Vue system Anti-A/Anti- B/ Anti-D Control Reverse diluents gel card for gel card grouping 
- All technical errors, errors in sampling, reagent errors were excluded.

- Discrepancies were solved according to discrepancy type protocol.

- Results of work-up were interpreted using a table (Grande-BB-SOP-01, page5)

\section{Results}

During 1 year, 9970 blood grouping tests were performed at Grande International Hospital (GIH). ABO discrepancies occurred 26 times with a frequency of $0.26 \%$ ( 1 per 384 samples). Male to female ratio was 42 to 58 . The discrepancies were found to be more prevalent in the child bearing age of 20-30 years (38\%) and age 30-40 (26\%). Discrepancies were most commonly found in patients with a history of pregnancy/miscarriage (30\%), history of carcinoma (23\%), and without any significant clinical history (23\%).

Table 1: History of patient with ABO discrepancy

\begin{tabular}{|l|c|c|}
\hline Patient's history & Frequency & Percent \\
\hline $\begin{array}{l}\text { Transfusion 3 months } \\
\text { previously }\end{array}$ & 1 & 3.8 \\
\hline $\begin{array}{l}\text { Second trimester pregnancy, } \\
\text { Transfusion history }\end{array}$ & 1 & 3.8 \\
\hline Acute renal failure & 1 & 3.8 \\
\hline Bone marrow transplant & 1 & 3.8 \\
\hline Carcinoma of breast & 1 & 3.8 \\
\hline Carcinoma of esophagus & 1 & 3.8 \\
\hline Carcinoma of pancreas/TB & 1 & 3.8 \\
\hline Chronic liver disease & 2 & 7.7 \\
\hline Sarcoma & 1 & 3.8 \\
\hline Lymphoma & 1 & 3.8 \\
\hline $\begin{array}{l}\text { Lymphoma under } \\
\text { chemotherapy }\end{array}$ & 1 & 3.8 \\
\hline Nothing Significant & 6 & 23.1 \\
\hline Pregnancy & 5 & 19.2 \\
\hline Pregnancy/ Hyperthyroidism & 1 & 3.8 \\
\hline $\begin{array}{l}\text { Pregnancy/ } \\
\text { Miscarriage before }\end{array}$ & 1 & 3.8 \\
\hline Transfusion history & 3.8 \\
\hline Total & 100.0 \\
\hline
\end{tabular}

The most common blood group involved was $B$ (34\%), followed by A (26\%), AB (23\%) \&O (17\%).
Table 2: Frequency of ABO discrepancy

\begin{tabular}{|l|c|c|}
\hline Blood Group & Frequency & Percent \\
\hline A positive & 7 & 26.9 \\
\hline B Positive & 7 & 26.9 \\
\hline B Negative & 2 & 7.7 \\
\hline AB Positive & 4 & 15.4 \\
\hline AB Negative & 2 & 7.7 \\
\hline O Positive & 4 & 15.4 \\
\hline Total & 26 & 100.0 \\
\hline
\end{tabular}

Reverse discrepancy type i.e. $96 \%$ with $84 \%$ extra antibody was resolved by incubating the sample at $37^{\circ} \mathrm{C}$ for $30-60$ minutes respectively signifying most probably $A$ and $B$ subgroups and auto/ allo antibodies.

Table 3: Methods of resolving the discrepancy

\begin{tabular}{|l|c|c|}
\hline Resolved by & Frequency & Percent \\
\hline $\begin{array}{l}\text { Room temperature for } 30 \\
\text { minutes }\end{array}$ & 1 & 3.8 \\
\hline At $4^{\circ} \mathrm{C}$ for 30 minutes & 3 & 11.5 \\
\hline At $37^{\circ} \mathrm{C}$ for 30 minutes & 10 & 38.5 \\
\hline At $37^{\circ} \mathrm{C}$ for 30 minutes & 5 & 19.2 \\
\hline At $37^{\circ} \mathrm{C}$ for 1 hour & 5 & 19.2 \\
\hline $\begin{array}{l}\text { tested with } \mathrm{A} 2 \text { cell and } \\
\text { tested at } 37^{\circ} \mathrm{C} \text { for } 1 \text { hour }\end{array}$ & 2 & 7.7 \\
\hline Total & 26 & 100.0 \\
\hline
\end{tabular}

\section{Discussion}

The study on analysis of $A B O$ discrepancies in 35 French hospitals showed the incidence of ABO discrepancies of 1 per 3400, most of which were due to phlebotomy errors, collection from wrong patient and clerical errors - in descending order ${ }^{10}$. Similar study done at a University hospital in Saudi Arabia showed 261 discrepancies in 549229 samples. The most common causes were errors of blood collection during phlebotomy and clerical errors ${ }^{11}$.

Another genomic study on 324 clinical samples showed that the number of definable alleles associated with $\mathrm{ABO}$ subgroups has increased from 14 to 29 from the earlier study ${ }^{12}$.

Clerical errors are common and are responsible for one third of transfusion related deaths. Mixup sample, phlebotomy errors, misidentification and the technical errors were found to be common in all other studied done previously. We have excluded all these errors in this study. 


\section{Conclusion}

1 per 384 discrepancies in this study emphasizes the need of considering ABO discrepanciesinblood banks for donors and recipients for safe blood transfusion to avoid any fatal complications. This discrepancy ratio is more than in other studied population of other countries. This incidence is also higher than $A B O$ mismatched transfusions at standard centers in Nepal. Repeat testing and investigating for $A B O$ subgroups and auto/ allo antibodies is important in patients with clinical significance or without any medical history.

\section{References}

1. Daniels G. Human blood groups. John Wiley \& Sons.2008.

2. Giangrande PL. The history of blood transfusion. Br J Haematol. 2000;110(4):75867.

3. Arumugam $\mathrm{P}$, Hamsavardhini $\mathrm{S}$, Ravishankar J, Bharath RR. Resolving ABO discrepancies by serological workup-an analysis of few cases. Int J Res Med Sci. 2017; 5(3):893-900.

4. Chapman JF, Elliott C, Knowles SM, Milkins CE, Poole GD et.al. Guidelines for compatibility procedures in blood transfusion laboratories. Transfus Med. 2004; 14(1):59-73.

5. Cangialosi TJ, Riolo ML, Owens S, Dykhouse VJ, Moffitt AH, Grubb JE et al. The ABO discrepancy index: a measure of case complexity. Am J Orthod Dentofacial Orthop. 2004; 125(3): 270-78.
6. Khan MN, Khan TA, Ahmed Z. Discrepancy in ABO Blood Grouping. J Coll Physicians Surg Pak. 2013; 23(8): 590-92.

7. Jawitz OK, G Jawitz N, Yuh DD, Bonde P. Impact of $A B O$ compatibility on outcomes Dier heart transplantation in a national cohort during the past decade. J HorDc Cardiovasc Surg. 2013;146: 1239-12946.

8. Milkins C, Berryman J, Cantwell C, Elliott C, Haggas $R$, et al. Guidelines for pretransfusion compatibility procedures in blood transfusion laboratories. Transfus Med. 2013; 23(1): 3-35.

9. Ansari S, Szallasi A.'Wrong blood in tube': Solutions for a persistent problem. Vox Sang. 2011;100(3): 298-302.

10. Chiaroni J, Legrand D, Dettori I, Ferrera V. Analysis of $A B O$ discrepancies occurring in 35 French hospitals. Transfusion. 2004;44(6):860-4.

11. Qutub H, ABIM A. Analysis of ABO Discrepancies Occurring at a University Hospital, Al-khobar, Saudi Arabia. Bahrain Med Bull. 2009;31(4).

12. Olsson ML, Irshaid NM, Hosseini-Maaf B, Hellberg Å, Moulds MK, Sareneva H, Chester MA. Genomic analysis of clinical samples with serologic $A B O$ blood grouping discrepancies: identification of 15 novel $A$ and $B$ subgroup alleles. Blood. 2001;98(5):1585-93. 